\title{
Olsalazine or sulphasalazine in first attacks of ulcerative colitis? A double blind study
}

\author{
S S C RAO, S A C DUNDAS, C D HOLDSWORTH, P A CANN, \\ K R PALMER, AND C L CORBETT
}

From the Royal Hallamshire Hospital, Sheffield, Western General Hospital, Edinburgh and District General Hospital, Worksop

SUMmaRy Olsalazine ( $2 \mathrm{~g} / \mathrm{day}$ ) and sulphasalazine ( $3 \mathrm{~g} / \mathrm{day})$ were compared in a double blind three centre trial in 37 patients presenting with first attack of distal colitis. Sigmoidoscopic appearances, rectal biopsies, and symptom and stool diary records were used to assess benefit and adverse effects. Both groups showed a similar decrease in stool frequency $(p<0 \cdot 001)$. The proportion of unformed stools was also decreased, but to a lesser extent $(\mathrm{p}<0.05)$ in those taking olsalazine $(78 \% v 55 \%$; $\mathbf{p}<0.001)$ compared with those taking sulphasalazine $(72 \% v 28 \% ; \mathbf{p}<0.001)$. There was a diminution in the proportion of stools containing blood in both groups (olsalazine: $61 \% v 22 \%$; p $<0.001 /$ sulphasalazine: $67 \% v 37 \% ; p<0.001)$. Sigmoidoscopic and histological appearances and clinical activity improved significantly and to a similar extent in both groups. Intolerance was encountered in two patients on olsalazine and four on sulphasalazine; intolerance to sulphasalazine being even higher (five of seven patients) in a preliminary study using a dose of sulphasalazine releasing the same amount of 5-aminosalicylic acid as $2 \mathrm{~g}$ olsalazine. Olsalazine was at least as effective as sulphasalazine in the treatment of new patients with distal colitis, and in a dose releasing an equivalent amount of 5 -aminosalicylic acid was better tolerated.

5-aminosalicylic acid has been shown to be the active therapeutic principle of sulphasalazine, ${ }^{1-3}$ and is useful in the treatment of ulcerative colitis. ${ }^{1-4}$ Its exact mechanism of action is not known but it may act by blocking prostaglandin synthesis in the mucosa ${ }^{5-7}$ and/or as an anti-oxidant by suppressing oxidative metabolism of polymorphonuclear leucocytes. ${ }^{\text {" }}$ Olsalazine consists of two molecules of 5-ASA linked together by an azo bond. ${ }^{~ " 1 "}$ After oral ingestion, most of the drug reaches the colon where it is split by colonic bacteria to release 5-ASA. ${ }^{411}$

Approximately $80 \%$ of patients intolerant of sulphasalazine can tolerate olsalazine..$^{11-13}$ In controlled trials of patients, a majority of whom were withdrawn from sulphasalazine, olsalazine has been shown to be superior to placebo in the treatment of

Address for correspondence: Dr C D Holdsworth, Gastroenterology Unit. Royal Hallamshire Hospital, Glossop Road, Sheffield S10 2JF.

Accepted for publication 14 October 1988. colitis $^{1+10}$ and as effective as sulphasalazine in maintaining remission. ${ }^{77}$ Its efficacy as primary treatment, however, has not been established.

In a randomised double blind, double dummy, multicentre clinical trial, we have compared the short term efficacy and tolerance of olsalazine and sulphasalazine in new patients presenting with colitis.

\section{Methods}

PATIENTS

All patients studied were outpatient referrals with their first attack of mild or moderately severe ulcerative colitis, ${ }^{1 \times}$ confirmed by sigmoidoscopic and histological evidence, and negative stool culture for pathogens. Patients were excluded if they had severe colitis or were considered sufficiently ill to require corticosteroids or had hepatic or renal dysfunction. The study was carried out in three centres, but 
Table 1 Details of patients at trial entry

\begin{tabular}{lcc}
\hline & Olsalazine & Sulphasalazine \\
\hline Patients (n) & 20 & 17 \\
Male:female & $9: 11$ & $8: 9$ \\
Mean age: years (range) & $46(19-77)$ & $42(21-71)$ \\
Mean duration of history: months & $3 \cdot 7(1-12)$ & $4 \cdot 4(0 \cdot 5-13)$ \\
$\quad$ (range) & & \\
Sigmoidoscopic appearance: & 3 & 0 \\
$\quad$ Mild & 9 & 10 \\
$\quad$ Moderate & 8 & 7 \\
$\quad$ Severe & $4 \cdot 3(1.9)$ & $3 \cdot 9(1.9)$ \\
Daily stool frequency (mean (SD)) & & \\
\hline
\end{tabular}

the majority of patients (32) were entered from Sheffield. The extent of disease was determined by sigmoidoscopy and/or barium enema. All of the patients had proctosigmoiditis or left sided colitis. The clinical details of the patients are shown in Table 1.

Patients were randomly allocated to receive either olsalazine or sulphasalazine along with physically indistinguishable dummies containing mainly potato starch. The drugs were provided in sealed blister packs and were taken four times a day in equally divided doses. At each visit the patients were asked to return the empty packs as a test of their compliance. The duration of the study was four weeks. At entry and at four weeks, the patients were assessed clinically and underwent sigmoidoscopy and rectal biopsy, and had blood samples taken for estimating haemoglobin, WCC, ESR, and liver biochemistry. They also provided stool samples for microbiological analysis and urine samples for analysis by dip sticks (BM-Test-5L, Boehringer). All patients were provided with diaries in which they recorded the date and time of defecation, the presence of blood and the consistency of stool (formed or unformed) and possible adverse effects. An interim clinical assessment was carried out at two weeks. Any patient who experienced an adverse effect was seen promptly and if necessary was withdrawn from the study.

Sigmoidoscopic appearance were graded as follows: normal $=0$, mild $=1$ (granular mucosa with minimal or no bleeding), moderate $=2$ (definite contact bleeding), severe $=3$ (spontaneous bleeding) . The rectal biopsy specimens were examined blind by one observer (SACD) and the degree of inflammation was graded as follows: absent $=\mathbf{0}$ (no evidence of inflammation), mild $=1$ (chronic glandular damage with definite increase in inflammatory cells), moderate $=2$ (changes of mild inflammation plus small foci of ulceration, severe $=3$ (changes of moderate inflammation plus crypt abscess formation and widespread ulceration). The clinical severity was graded using Truelove and Witts criteria. ${ }^{18}$ The disease was considered to be in remission if the stools did not contain any blood (macroscopically), there were no more than two bowel actions per day and there was no systemic disturbance. A scoring system was used in which a change of at least one grade constituted one point which was positive for improvement and negative for deterioration. Diary information was used to determine mean daily stool frequency, the percentage of stools that were unformed, and the proportion of bloody stools during the first three days and the last three days of treatment. Overall improvement was assessed and was defined as a positive change in at least two of the following criteria: sigmoidoscopic appearances, histological appearances, clinical severity, and percentage of bloody stools.

\section{TREATMENT REGIMEN}

In a preliminary study, we carried out a double blind, double dummy comparison of $2 \mathrm{~g}$ olsalazine with $4 \mathrm{~g}$ sulphasalazine (enteric coated), administered daily in four equally divided doses. All doses for the first three days contained placebo only, and the full daily dose was attained by gradual increase over a further four days. Eleven patients were entered in this study which was terminated as a high proportion of patients had experienced intolerable adverse effects. After breaking the code it was apparent that all four patients who had received olsalazine had tolerated the drug and improved clinically. In contrast, only two of the seven patients who received sulphasalazine tolerated the drug and improved clinically, the other five having to stop the drug because of intolerable adverse effects. These were nausea and dyspepsia in three patients, headache, dizziness, and arthralgia in one patient, and a rash in one other patient. All patients except the one who developed a rash, experienced adverse symptoms only after receiving the full dose of sulphasalazine, implying that the greater number of withdrawals was caused by dose related intolerance of sulphasalazine. The study was therefore redesigned using the same dose of olsalazine ( $2 \mathrm{~g} /$ day $)$ but a lower dose of enteric coated sulphasalazine ( $3 \mathrm{~g} /$ day). The drugs were, as before, provided in sealed blister packs and were administered four times a day, full dosage being attained gradually over seven days.

\section{ETHICAL CONSIDERATIONS}

The protocol for the study was approved by the Ethical Committee of the Sheffield Health Authority in October, 1984, and all patients gave a written informed consent.

STATISTICAL ANALYSIS

The significance of the differences in the stool 
Table 2 Changes in sigmoidoscopic appearance, histological grade, clinical and overall response

\begin{tabular}{|c|c|c|}
\hline & $\begin{array}{l}\text { Olsalazine } \\
(n=18)\end{array}$ & $\begin{array}{l}\text { Sulphasalazine } \\
(n=13)\end{array}$ \\
\hline \multicolumn{3}{|c|}{ Sigmoidoscopic response } \\
\hline Improved & $15(83 \%)$ & $11(84 \%)$ \\
\hline Unchanged & $3(17 \%)$ & $2(16 \%)$ \\
\hline Worse & 0 & 0 \\
\hline \multicolumn{3}{|c|}{ Histological response } \\
\hline Improved & $8(44 \%)$ & $6(46 \%)$ \\
\hline Unchanged & $10(56 \%)$ & $7(54 \%)$ \\
\hline Worse & 0 & 0 \\
\hline \multicolumn{3}{|c|}{ Clinical response } \\
\hline Improved & $16(89 \%)$ & $10(77 \%)$ \\
\hline Unchanged & $2(11 \%)$ & $3(23 \%)$ \\
\hline Worse & 0 & 0 \\
\hline \multicolumn{3}{|c|}{ Overall response } \\
\hline Improved & $15(83 \%)$ & $9(69 \%)$ \\
\hline Worse & 0 & 0 \\
\hline
\end{tabular}

No significant differences between treatments.

Table 3 Influence of treatment on stool pattern

\begin{tabular}{llllll}
\hline & \multicolumn{3}{c}{$\begin{array}{l}\text { Olsalazine } \\
(n=18)\end{array}$} & & \multicolumn{3}{l}{$\begin{array}{l}\text { Sulphasalazine } \\
(n=13)\end{array}$} \\
\cline { 2 - 3 } \cline { 5 - 6 } & Entry & 4 weeks & & Entry & 4 weeks \\
\hline $\begin{array}{c}\text { Daily stool frequency } \\
\text { (mean (SD)) }\end{array}$ & $4 \cdot 4(2 \cdot 0)$ & $2 \cdot 1(1 \cdot 2)^{*}$ & $3 \cdot 9(1 \cdot 7)$ & $1 \cdot 8(0 \cdot 6)^{*}$ \\
$\begin{array}{c}\text { Unformed stools (\% } \\
\text { of total for group) }\end{array}$ & 78 & $55^{*}$ & 72 & $28^{*}$ \\
$\begin{array}{c}\text { Bloody stools (\% of } \\
\text { total for group) }\end{array}$ & 61 & $22^{*}$ & 67 & $37^{*}$ \\
\hline
\end{tabular}

${ }^{*} \mathrm{p}<0 \cdot 001$.

frequency was determined by Student's paired $t$ tests. The significance of improvement in disease gradings was determined using Wilcoxson's paired rank-sum tests. The changes in the sigmoidoscopy, rectal biopsy and clinical severity scores (Table 2 ) were analysed using $\chi^{2}$ tests. The proportions of stools with different characteristics were compared using $\chi^{2}$ tests for multiway tables.

\section{Results}

PATIENT DETAILS

Thirty nine patients were entered into the new study, of whom 21 received olsalazine and 18 received sulphasalazine. During the final analysis, one patient was excluded from each group because of noncompliance. The two groups were well matched for age and sex distribution and for severity of disease activity (Table 1).
TOLERANCE

There were no drug related haematological or biochemical abnormalities in any of our patients. Stool examination was negative for pathogens and urine analysis showed no abnormalities, except in one patient who had glycosuria at entry, and was later diagnosed as having type II diabetes mellitus.

\section{Olsalazine}

Eighteen of $20(90 \%)$ patients tolerated this drug without any adverse effects. One patient experienced an exacerbation of diarrhoea and reported that the stools were predominantly watery rather than bloody. One other patient developed headache and nasal stuffiness. These adverse effects resolved after cessation of therapy.

\section{Sulphasalazine}

Thirteen of $17(76 \%)$ patients tolerated this drug. Adverse effects were encountered in four patients, of whom two experienced dyspepsia and nausea, one an exacerbation of bloody diarrhoea, and one myalgia, headache, and dizziness.

The difference in tolerance between the two groups was not statistically significant $\left(\chi^{2}=0 \cdot 45\right)$.

\section{STOOL FREQUENCY AND CONSISTENCY}

There was a similar improvement $(p<0 \cdot 001)$ in the mean daily stool frequency in both groups of patients (Table 2). An improvement $(\mathrm{p}<0.001)$ in the proportion of unformed stools was seen in both groups of patients, but patients in the olsalazine group showed a smaller reduction $(p<0.05)$ than patients in the sulphasalazine group (Table 2 ). There was a reduction $(\mathrm{p}<0.001)$ in the proportion of bloody stools in both groups of patients (Table 3 ).

\section{SIGMOIDOSCOPIC AND HISTOLOGICAL}

APPEARANCES

A similar proportion of both groups of patients showed an improvement in sigmoidoscopic $(\mathrm{p}<0 \cdot 01)$ and histological $(\mathrm{p}<0.01)$ appearances (Table 2).

\section{CLINICAL IMPROVEMENT}

There was an improvement in the clinical severity of disease $(p<0.001)$ and overall response $(p<0.01)$ in patients taking olsalazine and sulphasalazine. There was no difference in the clinical response between the two groups (Tables 2 and 3).

\section{Discussion}

Our study was unique in that none of the patients had received any other therapy for ulcerative colitis before entering the study. Previous trials have compared olsalazine with placebo in patients who were 
either withdrawn from sulphasalazine ${ }^{1+16}$ or were intolerant of this drug. ${ }^{12} 13$ Similarly, a large study which compared the relapse prevention properties of olsalazine and sulphasalazine was also conducted in patients whose sulphasalazine was withdrawn. ${ }^{17}$

We have clearly shown that on the basis of clinical response, sigmoidoscopic appearance, and histological changes that both drugs were effective in inducing a remission within one month in a high proportion of patients with mild or moderately active distal ulcerative colitis. None of the patients who tolerated the drug showed a deterioration in their disease activity. The histological improvement was not as striking as the improvement in sigmoidoscopic appearances or clinical response, and is consistent with previous observations $^{14}$ that there is a poor correlation between the three methods of assessment and that microscopic evidence of active disease may be seen in the absence of sigmoidoscopic or clinical evidence of activity. Hence, although histological assessment is a more accurate measurement of disease activity, therapeutic benefit assessed by histological improvement lags behind improvement in symptoms and sigmoidoscopic appearance.

Although there was a significant reduction in the proportion of stools which were unformed in both the groups, patients in the olsalazine group voided a significantly higher proportion of unformed stools compared with patients in the sulphasalazine group after but not before treatment. This may be explained by previous physiological studies which showed that olsalazine increases ileostomy output ${ }^{20}$ and reduces intestinal transit time, ${ }^{21}$ both of which could affect stool consistency whereas sulphasalazine does not cause any such effects. ${ }^{21}: 2$ In spite of this effect on stool consistency, there was a significant and comparable reduction in stool frequency. When assessed for clinical and overall improvement, a relatively higher proportion of patients taking olsalazine appeared to improve compared with sulphasalazine (Table 2), but this difference was not significant.

In our preliminary study we compared the two drugs using doses which released approximately equal amounts of 5-aminosalicylic acid in the colon. This study was terminated as many patients in the sulphasalazine group experienced intolerable adverse effects after receiving a daily dose of $4 \mathrm{~g}$ enteric coated sulphasalazine. A dose of $4.6 \mathrm{~g}$ sulphasalazine would have been required to produce equivalence in terms of 5-aminosalicylic acid release, to $2 \mathrm{~g}$ olsalazine. Moreover, even when prescribed a lower dose of sulphasalazine ( $3 \mathrm{~g} /$ day), a lower proportion of patients tolerated this drug. Thus, olsalazine was certainly better tolerated than sulphasalazine when given in comparable dosage, although it must be pointed out that our study was conducted in patients with distal colitis and the tolerance of olsalazine in this group may be different to that of patients with total colitis. ${ }^{12}$ In relapse prevention, which is the chief role of these drugs, it is established that $4 \mathrm{~g}$ sulphasalazine daily is more effective but tolerated by fewer patients than smaller doses. ${ }^{23}$ Acceptable tolerance by most patients in our study of $2 \mathrm{~g}$ olsalazine, which contains approximately as much 5-aminosalicylic acid as $4 \mathrm{~g}$ sulphasalazine, suggests that olsalazine could be the preferable drug.

We would like to thank Pharmacia Limited for the supply of the double dummy packs containing olsalazine capsules and sulphasalazine tablets, Sister Joy Farnsworth for her help throughout the study and $\mathrm{Mr}$ J Nichols for advice with statistics. Dr Rao was supported by a grant from the Trustees of the Former United Sheffield Hospitals.

Previously published in Abstract form in Gut 1988; 29: A705-6.

\section{References}

1 Khan AKA, Piris J. Truelove SC. An experiment to determine the active therapeutic moiety of Sulphasalazine. Lancet 1977: ii: 892-5.

2 Van Hees PAM, Bakker JH, Van Tongeren JHM. Effects of Sulphapyridine, 5-aminosalicylic acid and placebo in patients with idiopathic proctitis; a study to determine therapeutic moiety of Sulphasalazine. Gut 1980; 21: 632-5.

3 Klotz U. Maier K. Fischer C, Heinkel K. Therapeutic efficacy of Sulphasalazine and its metabolites in patients with ulcerative colitis and Crohn's disease. $N$ Engl J Med 1980; 303: 1499-5()2.

4 Dew MJ. Hughes P. Harries AD, et al. Maintenance of remission in ulcerative colitis with oral preparations of 5aminosalicylic acid. Br Med J 1982; 285 : 1012.

5 Sharon P, Ligumsky M, Rachmilewitz D, Zor U. Role of prostaglandins in ulcerative colitis. Gastroenterology 1978; 75: 638-40.

6 Sircar JC, Schwender CF, Carethers ME. Inhibition of soya bean lipoxygenase by sulfasalazine and 5aminosalicylic acid: a possible mode of action in ulcerative colitis. Biochem Pharmacol 1983; 32: 170-2.

7 Campieri M, Lanfranchi GA, Bazzocchi G, et al. Treatment of ulcerative colitis with high dose 5aminosalicylic acid enemas. Lancet 1981; ii: 270-1.

8 Miyachi Y, Yoshioka A. Imamura S, Niwa Y. Effect of sulphasalazine and its metabolites on the generation of reactive oxygen species. Gut 1987; 28: 190-5.

9 Willoughby CP, Aronsson JK, Agback H, Bodin NO, Truclove SC. Distribution and metabolism in healthy volunteers of disodium azodisalicylate in healthy subjects. A potential therapeutic agent for ulcerative colitis. Gut 1982; 23: 1081-7.

10 Lauritsen K, Hansen J, Ryde M, Rask-Madsen J. 
Colonic azodisalicylate metabolism determined by in vivo dialysis in healthy volunteers and patients with ulcerative colitis. Gastroenterology 1084; 86: 1496-500.

11 Rao SSC, Cann PA, Holdsworth CD. Clinical experience of the tolerance of Mesalazine and Olsalazine in patients intolerant of Sulphasalazine. Scand J Gastroenterol 1987; 22: 332-6.

12 Sandberg-Gertzen H, Jarnerot G, Kraaz W. Azodisal sodium in the treatment of ulcerative colitis. A study of tolerance and relapse prevention properties. Gastroenterology 1986; 90: 1024-30.

13 Meyers S, Sachar DB, Present DH, Janowitz HD. Olsalazine sodium in the treatment of ulcerative colitis among patients intolerant of Sulphasalazine: a prospective, randomised, placebo-controlled, double-blind, dose-ranging clinical trial. Gastroenterology 1987; 93: $1255-62$.

14 Selby WS, Barr GD, Ireland A, Mason CH, Jewell DP. Olsalazine in active ulcerative colitis. $\mathrm{Br}$ Med $J$ 1985; 291: 1373-5.

15 Zinberg J, Molinas S, Das KM. A double blinded, placebo controlled clinical study of Azodisalicylate sodium (Olsalazine) in the treatment of ulcerative colitis [Abstract]. Gastroenterology 1987; 92: A1711.

16 Hetzel DJ, Shearman DJC, Bochner F, et al. Azodisali- cylate (Olsalazine) in the treatment of active ulcerative colitis. A placebo controlled clinical trial and assessment of drug disposition. J Gastroenterol Hepatol 1986; 1: $257-66$.

17 Ireland A, Mason CH, Jewell DP. Controlled trial comparing Olsalazine and Sulphasalazine for maintenance treatment of ulcerative colitis. Gut 1988; 29: 835-7.

18 Truelove SC, Witts LJ. Cortisone in ulcerative colitis. Br Med J 1955; ii: 1041-8.

19 Truelove SC, Richards WCD. Biopsy studies in ulcerative colitis. Br Med J 1956; i: 1315-8.

20 Sandberg-Gertzen H, Jarnerot G, Bukhave K, Lauritsen K, Rask-Madsen J. Effect of azodisal sodium and sulphasalazine on ileostomy output of fluid, $\mathrm{PGE}_{2}$ and $\mathrm{PGF}_{2 \mathrm{a}}$ in subjects with a permanent ileostomy. Gut 1986; $27:$ 1306-11.

21 Rao SSC, Read NW, Holdsworth CD. Influence of Olsalazine on gastrointestinal transit in ulcerative colitis. Gut 1987; 28: 1474-7.

22 Rao SSC. Studies on the pathophysiology of bowel disturbance in ulcerative colitis. University of Sheffield: PhD thesis, 1987.

23 Khan AKA, Howes DT, Piris J, Truelove SC. Optimum dose of Sulphasalazine for maintenance treatment in ulcerative colitis. Gut 1980; 21: 232-40. 